\title{
LETRAMENTO CRÍTICO E ENSINO DE LÍNGUA INGLESA: INVESTIGANDO A CONSTRUÇÃO DA COMPETÊNCIA CRÍTICA DE APRENDIZES A PARTIR DA LEITURA DO CONTO “THE UGLY DUCKLING”
}

\author{
Critical Literacy and English Language Teaching: Investigating the \\ Construction of Learners> Critical Competence Based on the Reading of \\ the Tale "The Ugly Duckling"
}

\author{
Bruna da Costa TARGINO \\ Universidade Federal Rural do Semi-Árido \\ brunatargino@gmail.com \\ https://orcid.org/0000-0002-9796-0520 \\ Jeová Araújo ROSA FILHO \\ Universidade Federal Rural do Semi-Árido \\ jeova.araujo@ufersa.edu.br \\ https://orcid.org/0000-0002-9334-4747
}

\begin{abstract}
RESUMO: Este trabalho concerne de uma narrativa de experiência, vivenciada e fundamentada na implementação do projeto pedagógico "The different is not ugly". Com esta pesquisa, pretendemos compreender se e como seria possível desenvolver a competência crítica de aprendizes de língua inglesa, partindo da leitura de uma adaptação do conto de fadas The ugly duckling, originalmente escrito por Hans Christian Andersen. Para tanto, nos ancoramos numa concepção crítica de língua como discurso (FAIRCLOUGH, 2008), de texto como uma construção multimodal (ROJO, 2019) e experiência de aprendizagem como uma possibilidade de letramento crítico, organizada metodologicamente num ciclo de redesign de textos (JANKS, 2010). Em termos metodológicos, o presente estudo segue uma orientação qualitativa e configura-se como uma pesquisa-ação. Participaram do projeto alunos do $9^{\circ}$ ano de uma escola pública municipal, localizada na zona rural da cidade Apodi-RN. O desenvolvimento da prática deu-se em formato remoto, tendo em vista a situação pandêmica atual. A partir dessa experiência pedagógica pudemos observar que as tarefas desenvolvidas no decorrer do projeto colaboraram para o desenvolvimento da criticidade dos aprendizes, ao passo que os participantes se locomoviam dos sentidos literais para os sentidos ideológicos dos textos, conseguindo enxergar e debater sobre situações reais, mesmo tendo
\end{abstract}

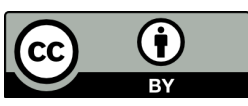


como base enquadramentos ficcionais da história "The ugly duckling". PALAVRAS-CHAVE: Letramento crítico; Conto; Projeto pedagógico; Bullying.

ABSTRACT: This work is a research narrative, foregrounded on the implementation of the pedagogical project "The different is not ugly". With this research we intend to understand if and how it was possible to develop the critical competence of English language learners through the reading of an adaptation of the tale "The Ugly Duckling", originally written by Hans Christian Andersen. Bearing that in mind, we are anchored on a critical conception of language as discourse (FAIRCLOUGH, 2008), of text as a multimodal construction (ROJO, 2019) and of the learning experience as a possibility of critical literacy, which can be methodologically organized in a cycle of text redesign (JANKS, 2010). In methodological terms, this study follows a qualitative orientation and is configured as an action research. The participants were 9th grade students from a municipal public school, located in the rural area of the city of Apodi-RN. The development of the practice took place in a remote format, in view of the current pandemic situation. From this pedagogical experience, we could observe that the tasks developed during the project contributed to the development of the apprentices' critical competence, as they moved from literal to ideological meanings of the texts, being able to see and position themselves in relation to real situations, even though based on fictional framings of the story "The ugly duckling". KEYWORDS: Critical literacy; Tale; Pedagogical project; Bullying.

\section{INTRODUÇÃO}

Como professores de língua, olhar para a nossa prática pedagógica a partir de uma ótica crítica significa compreender que podemos transformar a nossa realidade através da linguagem. Esse movimento também nos impele a percebermos a nossa sala de aula de uma maneira distinta, desafiando o terreno seguro das opiniões racionais e compreendendo como a aprendizagem pode ser uma experiência transformadora se explorarmos os sentimentos pessoais dos alunos. Horton e Freire (1990) defendem que, como pedagogos, devemos quebrar o status quo da nossa ação docente, questionando modelos tradicionais de ensino e estando conscientes de que não há criatividade sem ruptura com o antigo, sem um conflito a partir do qual somos levados a uma tomada de decisão.

Partindo do entendimento de que uma prática docente crítica refere-se a essa ruptura com o status quo, conforme aponta Horton e Freire (1990), o presente artigo 
apresenta uma narrativa de experiência através da qual buscamos elaborar reflexões e implicações pedagógicas a partir do uso de um conto de fada para o ensino de inglês numa perspectiva do letramento crítico. Num âmbito investigativo, buscamos compreender como a nossa prática pedagógica pode colaborar para a construção da competência crítica de aprendizes na aula de língua inglesa, tendo como base o desenho metodológico de letramento crítico proposto por Janks (2010), referido pela autora como ciclo de redesign.

Em termos organizacionais, propomos uma elaboração teórico-prática sobre o ensino crítico de língua inglesa. Partimos de um levantamento teórico, onde nos posicionamos em relação a conceitos fundamentais como discurso, criticidade e letramento crítico e seguimos para os desenvolvimentos pedagógicos e investigativos da pesquisa, através dos quais apresentamos uma proposta de ensino crítico e uma consequente investigação sobre as repercussões dessas práticas para a construção da competência crítica dos aprendizes.

\section{COMPREENSÃO DE LÍNGUA COMO DISCURSO}

Não há outra maneira de situarmos a nossa discussão acerca da pedagogia crítica de línguas se não partindo daquilo que nos parece o conceito mais fundamental da nossa prática pedagógica - a compreensão sobre língua. Fazendo referência a uma metáfora conceitual apresentada por Monte Mór (2011), a nossa ação docente pode ser compreendida holisticamente através da imagem de uma árvore. Nesse esquema conceitual, mesmo os aspectos mais visíveis, as folhas, estariam diretamente relacionadas com algo que permanece distante dos olhos, um enraizamento que, mesmo invisível, configura-se como de uma estrutura que nutre e alicerça toda a árvore. Tal qual uma árvore, mesmo os aspectos mais visíveis da nossa prática pedagógica - técnicas de ensino, esquemas de interação, recursos metodológicos etc. - estão diretamente relacionados com conceitos fundamentais ou mesmo crenças que fundamentam as nossas decisões nos contextos de ensino e aprendizagem. É, portanto, importante ter consciência sobre o enraizamento da nossa práxis e fazemos isso através do estudo teórico sobre aquilo que fundamenta as nossas escolhas.

Ao falarmos sobre perspectivas críticas para o ensino de línguas e, mais especificamente, sobre letramento crítico, partimos da compreensão de que língua não se trata meramente de um sistema linguístico. Isso porque a perspectiva estruturalista tem como fim a elaboração de um objeto de estudo delimitado cujas operações podem ser compreendidas a partir de uma lógica positivista. Aqui, defendemos que a língua trata-se de uma prática social e, portanto, está impelida às normas sociais, dispondo das mesmas 
características culturais e históricas da sociedade onde ela se manifesta. Dessa forma, como aponta Fromm (1979), a língua está profundamente relacionada à sociedade na qual ela se apresenta, de modo que há uma relação intrínseca entre língua e sociedade.

Em toda sociedade decomposta em classes sociais, existe uma concepção e uma ideologia predominante e estas concebem atribuições de sentido às palavras, que também são predominantes. Porém, o fato de existir uma imputação de sentido dominante revela que existem atribuições de sentido não predominantes ou dominadas. Neste contexto, a "plurivalência do signo" e A "polissemia da palavra", segundo Bakhtin (1990), exprimem este juízo de que existe um método de significação e ressignificação das palavras e que este é assinalado pelas conexões e conflitos sociais. A partir da constatação da natureza social da linguagem, torna-se incoerente usar das estratégias analíticas da linguística estruturalista de Saussure para a compreensão do fenômeno linguístico, pois essa vertente investigativa se sinaliza unicamente formal e descritiva em relação a um sistema linguístico e não considera a materialidade da prática social.

Com base nestas considerações sobre linguagem, podemos avançar para nossa ponderação sobre o discurso. Primeiramente, é necessário atribuir uma definição sobre o que é o discurso. Afinal de contas, discurso e linguagem são a mesma coisa? A concepção de linguagem é muito extensa, pois ela concerne todos os processos simbólicos, sejam gráficos ou sonoros de uma sociedade, como forma de viabilizar a comunicação entre as pessoas. Ademais, a linguagem em uma sociedade tida como de classes é atravessada pela multiplicidade dos sentidos de uma palavra. O discurso, por sua vez, não pode ser designado como a linguagem, isto se dá primeiramente pelo fato de que o discurso e a linguagem não são uma só coisa, pela mesma razão que a linguagem é sobretudo uma forma de expressão, ao passo que o discurso é basicamente expressão. Isto é, o discurso se apresenta por meio da linguagem, já a linguagem, é a forma de exteriorização do discurso. Todo discurso é manifestado por intermédio da linguagem, porém, a linguagem pode ser condutora de vários discursos.

Podemos, portanto, definir o discurso como sendo uma manifestação palpável e circunscrita da linguagem. Em outras palavras, o discurso é algo sólido e demarcado. Deste modo, o discurso é uma amostra própria, característica, real da linguagem, sendo em sua totalidade coesivo e ordenado, ainda que o nível de coerência e estruturação seja alterado a depender do discurso. Ou seja, esses aspectos são mantidos dependendo de quem discursa.

Numa consideração crítica sobre discurso, nos ancoramos nas contribuições de Fairclough (2008) ao considerar discurso como um modo de ação, uma maneira simbólica 
através da qual as pessoas podem agir e transformar as realidades, assim como um modo de representação. De acordo com o autor, a concepção crítica de discurso precisa ser compreendida em relação à estrutura social. Esta relação seria dialética ao passo em que o discurso é moldado e restringido pela estrutura social, o que significa dizer que o discurso é "socialmente constitutivo" (p. 91). Nesse sentido, o discurso configura todas as dimensões da estrutura social e não seria apenas uma prática, nem apenas uma representação do mundo, mas sim uma maneira de constituirmos e construirmos o mundo em significado. São exatamente a partir desses processos de significação discursivos que construímos identidades sociais, os nossos posicionamentos subjetivos, as nossas relações sociais e até mesmo o sistema de conhecimentos e crenças ao qual nos referimos como verdade.

\section{SOBRE A PEDAGOGIA CRÍTICA}

As práticas pedagógicas que efetivamente dão abertura para o diálogo acerca de questões sociais, de fundamental importância na sociedade globalizada, tornaramse imprescindíveis ao longo das últimas décadas. Essas práticas estão relacionadas diretamente ao conceito de pedagogia crítica e se configuram como uma leitura crítica do mundo, permitindo que os aprendizes se tornem autônomos e conscientes de seus posicionamentos ideológicos.

Freire (1970) debruçou-se sobre uma análise marxista dos sistemas educacionais, através da qual se propôs a identificar os motivos que acarretaram o insucesso de transformar a sociedade através da educação, como forma de modificar esse panorama. O educador buscava oferecer uma alternativa educacional viável, firmada no diálogo e no pensamento crítico para transformar a sociedade. Neste seguimento surgiram outros teóricos, como Giroux (2010), os quais, sob a influência de Freire (1967) ou através de conclusões semelhantes, deram continuidade ao paradigma educacional que hoje chamamos de pedagogia crítica.

Ao contrário dos métodos preponderantes de ensino, a pedagogia crítica preconiza que um dos papéis fundamentais do educador é assegurar que o futuro indique um acesso para uma sociedade mais justa, um mundo onde os discursos do crítico funcionem como sendo parte de um projeto democrático mais abrangente, a fim de modificar a realidade, de modo a oferecer mais oportunidades àqueles que vivem à margem da sociedade. Dessa forma, a pedagogia crítica se propõe a apresentar novas formas de pensar criticamente e agir. 
Essa abordagem sugere que a educação é o lugar onde o indivíduo e a sociedade começam a desenvolver pensamentos e características críticas sobre determinadas situações, uma ação social que pode empoderar os alunos. Na sala de aula sugerida pelas ideias de Freire (1970), os professores abordam problemas derivados da vida do aluno, questões sociais e disciplinas acadêmicas em um diálogo criado mutuamente. Essa pedagogia desafia professores e alunos a se capacitarem para a mudança social, para promover a democracia e a igualdade à medida que são desenvolvidas práticas de letramento.

A pedagogia crítica requer que os alunos questionem o conhecimento existente como parte dos hábitos de questionamento apropriados para os cidadãos em uma democracia. E seguindo esse paradigma, o professor crítico também deve ser democrático. Se o professor critica a desigualdade e a falta de democracia na sociedade, mas por outro lado, ensina de forma autoritária, ele compromete sua credibilidade. A pedagogia crítica sugerida por Freire (1967), configura-se como uma relação democrática e transformadora entre alunos e professores, e alunos e sociedade. Em outros termos, a pedagogia crítica Freireana, defende a libertação dos conceitos tradicionais de escola e professor. A instituição de ensino passa a ser vista como um palco para debates e construção de conhecimento.

Essa perspectiva desafia uma perspectiva de educação na qual se compreende o professor como o detentor do conhecimento, os alunos como páginas em branco, a escola como único local de aprendizagem e as práticas pedagógicas como um ato de transmissão de saberes. É, nesse sentido, que Freire (1970) lança mão de uma metáfora conceitual de educação bancária para ilustrar como a pedagogia crítica se configura como uma mudança paradigmática:

A educação torna-se assim um ato de depósito, em que os alunos são os depositários e o professor é o depositante. Em vez de se comunicar, o professor emite comunicados e faz depósitos que os alunos pacientemente recebem, memorizam e repetem.... No conceito bancário de educação, o conhecimento é um dom concedido por aqueles que se consideram conhecedores daqueles que consideram não saber nada. Quanto mais os alunos trabalham no armazenamento dos depósitos que lhes são confiados, menos desenvolvem a consciência crítica que resultaria da sua intervenção no mundo como transformadores desse mundo (p. 58 - 60).

Freire (1967) aponta definições que se fizeram essenciais para a pedagogia crítica. Ainda que não tenha focado no ensino de línguas estrangeiras em suas análises e obras, 
suas contribuições filosóficas vêm sendo implementadas nos estudos acerca do ensino crítico de línguas como forma de resgatar o reconhecimento e importância da adequação do contexto social e cultural dos aprendizes durante as aulas.

A inserção da realidade do aprendiz no contexto de ensino de leitura crítica é examinada por Freire (1970), o autor aponta que a leitura do mundo antecede a leitura de palavras. Desta forma, a pedagogia crítica resulta na leitura das esferas sociais a partir das quais determinado texto foi desenvolvido e com base em quais é lido. Assim dizendo, se faz necessário um conceito de pedagogia como uma prática social, que abrange diferentes tipos de conhecimento que atuem dentro dos processos interpretativos: conhecimento linguístico textual, conhecimento prévio e de práticas sociais gerais e discursivas.

É, portanto, a partir dessas considerações que traçamos aquilo que compreendemos por termos como criticidade, ser crítico ou ter consciência crítica. Em linhas gerais, o crítico se refere à possibilidade de se envolver em práticas discursivas que desafiem aquelas de ordem dominantes e convencionalizadas. Para fazer isso, de acordo com Luke (2018), é necessário um esforço de reposicionamentos. Precisamos sair de nossos próprios centros para experimentarmos a posição do outro e esse processo de construção de alteridade acontece através do distanciamento ou estranhamento de discursos dominantes.

\section{LETRAMENTO CRÍTICO: CONCEITO E DESENHO METODOLÓGICO}

A expressão "letramento" surgiu no Brasil na década de 1980. O termo aparece como tradução para palavra literacy no livro No mundo da escrita de Mary Kato, publicado em 1986. Porém, somente no ano de 1988 o termo "letramento" passa a ser definido tecnicamente no livro “Adultos não alfabetizados: o avesso do avesso”, de Leda Tfouni. Para a autora, "o letramento focaliza os aspectos sócio-históricos da aquisição de um sistema escrito por uma sociedade" (TFOUNI, 1988, p. 20), diferenciando-se da definição de alfabetização, que é conceituada por Rojo e Moura (2019) como "a ação de se apropriar do alfabeto, da ortografia da língua que se fala” (p. 15). Com o início de um novo milênio, a conceituação em torno do termo letramento e as suas funcionalidades seguiram se manifestando. Para Rojo e Moura (2019):

O termo letramento busca recobrir os usos e práticas sociais de linguagem que envolve a escrita de uma maneira ou de outra, sejam eles socialmente valorizados ou não, locais (próprios de uma comunidade específica) ou globais, recobrindo contextos sociais diversos (família, igreja, trabalho, mídias, escola etc.), em grupos sociais e comunidades culturalmente diversificadas. Difere, portanto, acentuadamente, tanto do conceito de alfabetização quanto do de alfabetismo(s). Letramento(s) é 
um conceito com uma visada socioantropológica; alfabetismo(s) é um conceito de base sociocognitiva; a alfabetização designa uma prática cujo conceito é da natureza linguístico-pedagógica (p. 16).

Neste contexto, podemos, portanto, dizer que letramentos são as múltiplas formas de atuar sobre os mais diversos contextos sociais e culturais por meio da escrita. Logo, considerando a diversidade de culturas que implicam diretamente nas diferentes esferas sociais. Para Rojo e Moura (2019), as diversas práticas letradas são contextuais e têm regimes particulares, os quais são compostos por participantes, linguagens e distribuições de poderes.

Por meio da globalização, surgiram novos e mais modernos meios de comunicação, destacando-se também, novas formas de textos. Os textos escritos abriram caminho para os discursos radiofônicos, cinematográficos, televisivos e digitais. À medida que pesquisamos como os letramentos são multimodais, observamos muitas maneiras pelas quais o sujeito constrói significado - através de teatro, música, arte, tecnologia, bem como a escrita. Através do processo de implementação dessas práticas, a humanidade foi transportada dos letramentos de textos escritos, para os multiletramentos.

O termo multiletramentos foi aderido como o modelo para comportar e evidenciar o resultado dessa soma de práticas sociais, controle e aplicações dos diferentes códigos de linguagem e tecnologia. À sombra dos multiletramentos, apontamos o letramento crítico, por compreendermos que é nosso objeto de estudo, e sobre ele discorreremos a seguir. Para Brydon (2011):

O mundo contemporâneo requer habilidades de letramento avançadas e isto inclui a capacidade de pensar criticamente, incluindo contextualização, análise, adaptação, tradução de informação e interação entre os indivíduos dentro e além de sua comunidade (p. 105).

Os estágios do letramento crítico estão vinculados à pedagogia crítica legitimada por Freire (1998), que afirma que leitura de mundo prepondera a leitura da escrita propriamente dita, permitindo ao leitor se posicionar de modo crítico no contexto social em que este esteja inserido. Com base nessa perspectiva, é possível reconhecer que isso acontece por conta de uma junção de ações e análises sobre o meio no qual o indivíduo está inserido e sua intenção de modificá-lo.

Para Janks (2010), o letramento crítico consiste em permitir que os aprendizes leiam a palavra e o mundo em relação a questões como poder, diversidade e acesso. Deste modo, as práticas de letramento crítico partem de um estranhamento sobre a linguagem 
como uma materialidade neutra e buscam levar os aprendentes a compreenderem as maneiras como os discursos podem ser usados tanto para manter quanto para desafiar formas existentes de poder.

A partir dessas considerações, Janks (2010), em seu livro Literacy and power, propôs um esquema metodológico para a orientação de práticas pedagógicas calcadas na possibilidade de desenvolvimento de letramento crítico, ao que a autora nomeia como um ciclo de redesign de textos, conforme apresentado na figura abaixo:

Figura 1: Ciclo de redesign.

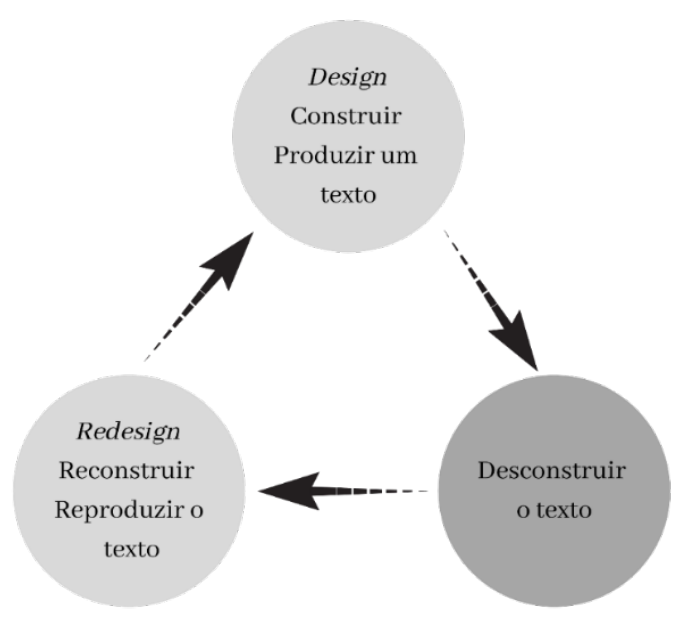

Fonte: Janks (2010).

O ciclo apresentado por Janks (2010) é um movimento de compreensão do design de textos e de reconstrução dessas realidades simbólicas, ao que a autora se refere como redesign. Segundo a autora, um olhar crítico para o design de textos nos leva à percepção de como são escolhidos e aparelhados os textos verbais e não verbais para criação de significados na construção de significado das palavras, imagens, sons, entre outros. É no âmbito do design que direcionamos o nosso olhar para o emaranhado de signos que compõem um texto, de modo que possamos compreender como sentidos são desenvolvidos, como posicionamentos são adotados, como atribuímos formas a um texto e toda essa experiência torna-se um processo de construção crítica fundamental para o redesign dos nossos próprios textos e dos textos dos outros.

$\mathrm{O}$ redesign, portanto, contribui para o desenvolvimento de um mundo em que o poder não seja usado como meio de deslegitimar o empoderamento dos outros, com o 
propósito de que a diferença seja percebida, legitimada e que as práticas de produção de textos sejam manifestações democráticas e acessíveis a todos.

\section{CONTEXTO DE INVESTIGAÇÃO E PARTICIPANTES}

Para o desenvolvimento pedagógico e investigativo desta pesquisa, foi selecionada uma turma de $9^{\circ}$ ano, que contava com vinte alunos de uma escola municipal do distrito de Soledade, zona rural da cidade de Apodi-RN, a partir da elaboração de um questionário de perfil dos participantes, implementado através da plataforma Google Forms, conseguimos gerar informações mais assertivas em relação aos participantes e às possibilidades de contato para futuras etapas da pesquisa. O questionário foi dividido em três sessões e teve como objetivo traçar informações pessoais, compreender a relação dos aprendizes com ensino remoto na disciplina de Língua Inglesa, assim como a sua relação com práticas de leitura em LI.

A partir dos dados gerados no questionário de perfil dos participantes, pudemos perceber que a faixa etária da turma variava entre quatorze e quinze anos. Consideramos esse contexto ideal para o desenvolvimento da pesquisa, uma vez que que participantes dessa faixa etária vivem experiências de adolescência que seriam amplamente discutidas durante as aulas.

Outro aspecto significativo está no fato de todos os alunos serem residentes do Distrito de Soledade, o que facilitou as condições de desenvolvimento prático da pesquisa. Além disso, consideramos importante investigar as condições de acesso à internet, já que toda a elaboração prática da pesquisa aconteceria em modo remoto. Em relação a isso, no questionário de perfil dos participantes investigamos se os estudantes tinham conexão com a internet e quais seriam os meios de acesso. Todos os alunos afirmaram ter conexão e, em sua maior parte, o acesso à rede acontecia através de celulares.

A partir dos dados de acessibilidade apresentados nos questionários, elaboramos estratégias para o desenvolvimento do âmbito pedagógico e investigativo da pesquisa. Assim, os recursos de tecnologias digitais para elaboração de atividades síncronas e/ou assíncronas, bem como a comunicação com a turma durante a realização da pesquisa precisaram ser compatíveis com celulares. A partir dessas observações, foi criado um grupo no WhatsApp através do qual um total de quatorze, dos vinte alunos da turma selecionada entraram e se tornaram participantes dessa pesquisa.

Em cumprimento com questões éticas de pesquisa envolvendo participantes menores de idade, elaboramos dois documentos que atestam a nossa responsabilidade com os estudantes e com a instituição escolar onde a pesquisa se desenvolveu. Os documentos 
referem-se a um Termo de Consentimento Livre e Esclarecido (TCLE), enviado aos pais dos participantes, e um Termo de Anuência, enviado à direção da escola.

\section{PERCURSO PEDAGÓGICO E INVESTIGATIVO DA PESQUISA}

Como já apresentado anteriormente, esta pesquisa-ação teve como objetivo central observar se e como as práticas de leitura do conto The ugly duckling contribuíram para o desenvolvimento crítico dos aprendizes de língua inglesa. Para alcançar tal objetivo, o desenho metodológico deste estudo foi construído sob um âmbito pedagógico e investigativo. O primeiro, corresponde aos procedimentos metodológicos para o desenho e implementação de um projeto pedagógico. Já o segundo, consistiu na geração e subsequente análise de dados. A Figura 2 abaixo ilustra a organização de cada um dos âmbitos dessa pesquisa:

Figura 2: Desenho metodológico da pesquisa.
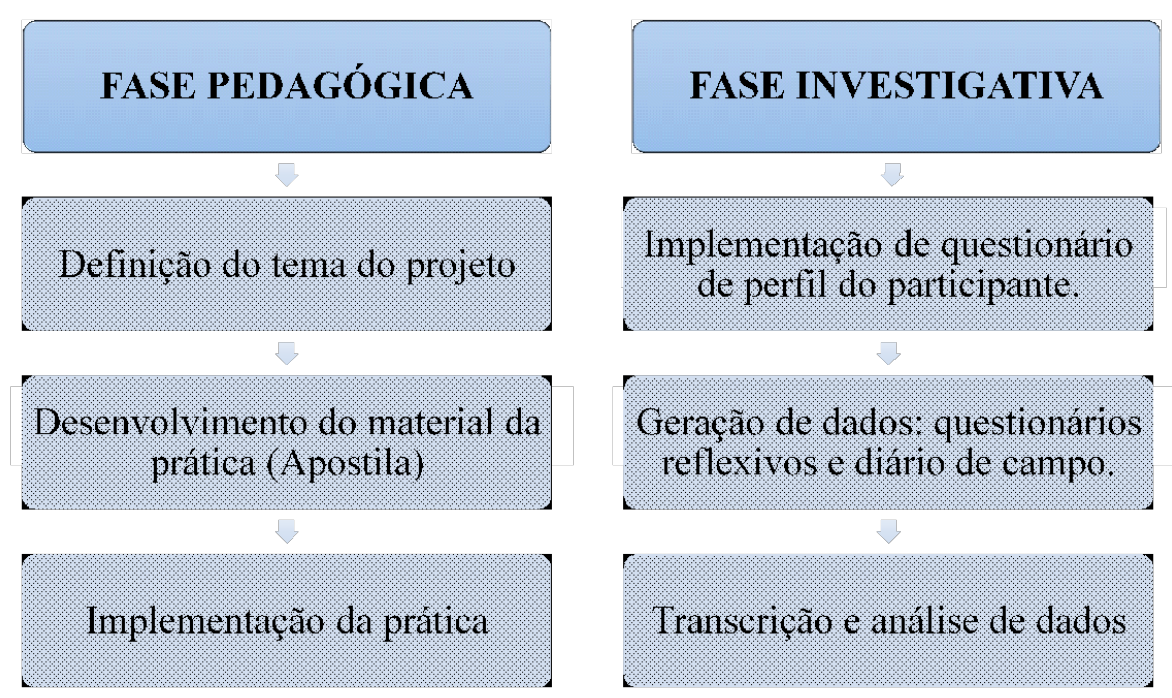

Fonte: Os autores (2021).

\section{O PROJETO PEDAGÓGICO DE INTERVENÇÃO}

A implementação do âmbito pedagógico desse projeto de pesquisa foi desenvolvida através da promoção de atividades remotas síncronas e assíncronas em decorrência da situação pandêmica atual. Além das apresentações, dinâmicas e questionários online, foi 
pensado e desenvolvido um material de apoio com intuito de oferecer suporte didático aos aprendizes no decorrer das atividades programadas. $\mathrm{O}$ material foi recebido pelos alunos na ocasião da entrega dos livros didáticos, na própria instituição escolar.

Considerando os contos de fadas como principal suporte para o desenvolvimento dos objetivos almejados, os encontros foram desenvolvidos com o propósito de engajar os aprendizes em experiências de aprendizagem de língua inglesa que os movessem entre os sentidos literais, metafóricos e ideológicos construídos a partir da leitura de uma adaptação do conto The Ugly Duckling (O patinho feio), de Hans Christian Andersen.

"O Patinho Feio" é uma narrativa sobre as peripécias e complicações de um pequeno cisne que nasceu em um ninho de uma pata. Logo ao nascer, o pequeno foi apontado como diferente, a partir de então, uma série de problemas começaram. Sua aparência foi o motivo para que outros animais e a sua própria família o excluísse, as humilhações levaram o jovem cisne a sair de casa em busca de um bando que o acolhesse. No entanto, a sua caminhada longe de casa, até o encontro com os cisnes, também foi marcada por abusos contra a sua aparência.

Segundo Tearle (2020), alguns aspectos da história fizeram com que muitos leitores da época em que o conto fora publicado especulassem sobre a existência de uma relação entre o escritor e o personagem principal do conto, sugerindo uma teoria bastante utópica de que Hans na verdade, não era filho biológico de seus pais, e sim, filho do Príncipe Christian Frederik, que mais tarde tornou-se o rei Christian VIII da Dinamarca. É improvável que seja verídica tal especulação, entretanto, é inevitável que os contos de fadas abram portas para as mais diversas interpretações freudianas e biográficas. Além disso, segundo relatos, o próprio Andersen foi uma criança atrapalhada que sofreu bullying na escola. Mais tarde, ele disse que seus tempos de escola foram os mais sombrios de toda a sua vida, e podemos pressupor que as próprias experiências de Andersen alimentaram a narrativa do conto "O Patinho Feio".

O conto possibilita interpretações importantíssimas, podendo ser compreendido como uma fábula moral sobre a questão de exclusão social pelo fato de o indivíduo não ser detentor da "beleza" convencional, por não se enquadrar nos padrões propostos, ou pode ser interpretada como uma história que preconiza o valor da perseverança. Deste modo, em sua narrativa, Andersen faz uma ligação evidente entre as relações com as pessoas e o conto. Partindo da ideia de que tudo que é diferente está errado ou que é difícil funcionar em um mundo onde as diferenças não são muito compreendidas.

Assim, consideramos o trabalho de despertar a criticidade do aprendiz por meio de uma narrativa cultural, como a de Andersen, como uma via de alerta sobre a questão do bullying recorrente na instituição selecionada para o desenvolvimento da prática. 
O intuito da utilização deste conto está relacionado com a reflexão sobre o letramento crítico proposto neste trabalho. A partir das experiências de leitura, foi pretendido que os aprendizes pudessem desenvolver o seu senso de criticidade, estando aptos para participarem dos debates estabelecidos a partir do conto abordado. Partindo dessa perspectiva, propusemos o desenvolvimento de encontros planejados para serem implementados no decorrer de cinco momentos.

É importante mencionar que para planejamento pedagógico desta prática, tivemos como ponto de partida o ciclo de design e redesign proposto por Janks (2010). De acordo com a autora, o design diz respeito à compreensão e à ação através dos sentidos imbuídos num texto, à concepção sobre como signos e símbolos se materializam através de palavras, leiaute, imagens, cores, fontes, movimentos, som e outros mais, e a capacidade de usarmos tais recursos simbólicos para construirmos sentidos e agirmos sobre o mundo.

Já o redesign, compreende a uma desconstrução das ordens simbólicas dos textos que nos são apresentados e da possibilidade de reconstrução de realidades alternativas. Em termos práticos, o redesign é, por exemplo, sobre opor-se ao bullying, sobre sermos antirracistas, é sobre desafiar as normatividades que se vestem de "naturais". Isto é, se trata de uma luta por direitos democráticos cujo local de embate é precisamente o discurso.

Outro ponto de partida igualmente importante para o desenvolvimento do projeto pedagógico foi a compreensão de leitura como uma prática multimodal. Isso porque a nossa perspectiva sobre texto não é reduzida apenas aos signos escritos. Aqui, nos ancoramos nas considerações de Rojo (2019) ao postular que os textos, sejam eles escritos, impressos ou digitais, são invadidos por todas as modalidades de linguagens e semioses que "se mesclam sem a menor cerimônia" (p.11).

Além disso, especialmente agora no contexto de Ensino Remoto, em que muitas das nossas práticas pedagógicas são mediadas pelas Tecnologias da Informação e Comunicação TICs, pensar no desenvolvimento de práticas de leitura e letramento crítico é algo intrinsecamente relacionado com as dinâmicas de um mundo digital e cibernético, marcado pela constituição de um espaço (a internet) participativo, colaborativo e distribuído. Em outros termos, um espaço menos autorado, de livre informação e caracterizado pela cultura do remix e da hibridação (Rojo, 2019).

Levando em consideração o desenho metodológico do ciclo de redesign e a concepção de leitura como prática crítica e multimodal, o projeto pedagógico foi elaborado a partir da seguinte organização geral: 
Quadro 1: Organização do projeto The Different is not Ugly.

\begin{tabular}{|c|c|c|}
\hline $\begin{array}{l}\text { Ciclo de redesign } \\
\text { (JANKS, 2010) }\end{array}$ & Desenho metodológico & Práticas desenvolvidas \\
\hline \multirow{3}{*}{ Design } & $\begin{array}{c}\text { INTRODUCTION } \\
\text { Apresentação do projeto "The } \\
\text { Different is not Ugly" }\end{array}$ & $\begin{array}{l}\text { AULA ASSíNCRONA 1: } \\
\text { - } \quad \text { (Vídeo) Apresentação da prática } \\
\text { - } \quad \text { Sugestão de game para leitura } \\
\text { do conto em inglês (Fairy Tales, } \\
\text { Children's Books, Stories and } \\
\text { games) } \\
\text { HOMEWORK: } \\
\text { - (Apostila) Leitura do conto The } \\
\text { Ugly Duckling. } \\
\text { (Apostila) Dinâmicas pós } \\
\text { leitura. }\end{array}$ \\
\hline & $\begin{array}{c}\text { READING } \\
\text { COMPREHENSION: } \\
\text { Exploração de aspectos de } \\
\text { compreensão textual }\end{array}$ & $\begin{array}{l}\text { AULA SÍNCRONA 1: } \\
\text { - Debate sobre as primeiras } \\
\text { impressões do texto The Ugly } \\
\text { Duckling. } \\
\text { - Estudo do vocabulário } \\
\text { (Adjectives) + (To be). } \\
\text { HOMEWORK: } \\
\text { (Apostila) Atividade de } \\
\text { produção de frases, utilizando } \\
\text { os adjetivos retirados do conto. }\end{array}$ \\
\hline & $\begin{array}{c}\text { CRITICAL READING: } \\
\text { Desenvolvimento da criticidade } \\
\text { através das práticas de leitura }\end{array}$ & $\begin{array}{l}\text { AULA SÍNCRONA 2: } \\
\text { - } \quad \text { Debate em torno do } \\
\text { questionamento “Por que o } \\
\text { 'Patinho Feio' era considerado } \\
\text { feio?” } \\
\text { - } \quad \text { Questionário } \\
\text { HOMEWORK: } \\
\text { - Google Forms) Questionário } \\
\text { sobre o posicionamento dos } \\
\text { aprendizes acerca de padrões } \\
\text { estéticos. }\end{array}$ \\
\hline
\end{tabular}


AULA ASSÍNCRONA 2:

- (Vídeo) Apresentação de sugestões e modelos para recriação do conto The Ugly Duckling.

\section{HOMEWORK:}

- Recriar o conto através de: Campanha Instagram/grupos da escola/ Confecção de história em quadrinho ou Cartazes.

\section{AULA SÍNCRONA 3:}

- Apresentação dos projetos desenvolvidos pelos aprendizes.

Fonte: Os autores (2021).

A primeira fase, cujo enfoque foram práticas de compreensão do design dos textos, foi dividida em três etapas, a saber: Introduction, Reading Comprenhension e Critical Reading.

A primeira etapa do projeto, Introduction, teve como objetivo central apresentar a proposta temática e engajar os aprendizes num primeiro contato com a leitura do conto. Para isso, enviamos um vídeo explicativo para a sala virtual (grupo do WhatsApp), com o intuito de apresentar os objetivos e dinâmica do projeto, bem como o material desenvolvido a ser utilizado nos encontros seguintes. Além da apresentação da prática, orientamos os alunos quanto à realização da primeira atividade: a leitura do conto The Ugly Duckling, acompanhada da tradução feita pelos pesquisadores, propícia ao nível de compreensão linguística dos aprendizes.

Já a segunda etapa, Reading Comprenhension, teve como objetivo averiguar o nível de compreensão literal dos aprendizes, a partir da leitura do conto. Para tanto, foi realizado o primeiro encontro síncrono, na ocasião debatemos sobre as primeiras impressões dos aprendizes acerca da leitura. As atividades realizadas durante esse encontro giravam em torno do vocabulário retirado do conto, mais precisamente os adjetivos e para o homework, foi solicitado que os aprendizes elaborassem um pequeno parágrafo em inglês, apontando quais dos adjetivos estudados eram condizentes com a personalidade de cada um. Buscou-se perceber a habilidade dos aprendizes em desenvolver frases utilizando os adjetivos retirados do conto. 
A terceira etapa foi denominada Critical Reading. A partir desse momento, buscamos observar a criticidade dos aprendizes. Para tal, realizamos um encontro síncrono no qual foi levantado um debate sobre questões relacionadas ao conto e situações reais. Foi implementado um questionário, a fim de compreender o posicionamento de cada um dos participantes, caso não houvesse a participação oral no momento síncrono.

Seguindo para a fase de Redesign, temos a última etapa da prática pedagógica, a qual nos referimos como Creating, o momento de culminância do projeto, no qual buscamos compreender o desenvolvimento da criticidade dos alunos através da produção de textos (cartazes, história em quadrinho, vídeo, campanha em redes sociais), como meio para recriar o conto. Ainda como parte da etapa de Creating, foi enviado um segundo questionário, através da plataforma Google Forms, para que os aprendizes pudessem compartilhar suas opiniões e pontos de vista com base nas atividades desenvolvidas durante a prática.

\section{ANÁLISE E RESULTADOS}

Como o objetivo central desta pesquisa foi observar se e como as práticas pedagógicas vivenciadas contribuem para o desenvolvimento crítico dos aprendizes de Língua Inglesa, o fundamento investigativo para essa descrição é de ordem discursiva. Assim compreende-se que é através do discurso que se performa a criticidade e, portanto, somente através de uma análise discursiva pode-se traçar qualquer conclusão. Assim, em termos de análise, o presente estudo buscou sistematizar discursos apresentados em momentos de interação, questionários e atividades pedagógicas a partir de um viés reflexivo, crítico e descritivo. Aqui, trazemos como enfoque de análise as etapas de Critical Reading e Creating, uma vez que esses momentos são mais representativos para a nossa observação sobre a construção da criticidade.

\section{CICLO DE REDESIGN: ETAPA DE CRITICAL READING}

Para a introdução das tarefas desta etapa de Critical Reading, apresentamos algumas imagens, vídeos e matérias de jornais, seguidas de perguntas que explorassem o senso crítico de cada um dos participantes. Na primeira imagem, apresentamos uma foto real de um filhote de pato descrito tal qual os filhotes relatados no conto. A imagem foi exibida com a finalidade de demonstrar o padrão narrado como "bonito" no conto de Andersen, juntamente com a pergunta "Is this baby cute?". A maioria dos participantes utilizaram o chat para responder de forma positiva acerca da aparência do filhote 
apresentado. No material disponibilizado para os alunos, também deixamos o espaço para que os alunos respondessem, caso não se sentissem completamente à vontade para responderem naquele momento. Em seguida, apresentamos uma nova imagem de um filhote de cisne, cuja descrição do conto aponta o pequeno animal como "feio". Da mesma forma, como na imagem anterior, procuramos compreender o posicionamento da turma.

De modo geral, as respostas também foram positivas. Além disso, a imagem chamou atenção de alguns participantes que afirmaram não conhecer um cisne filhote. Imaginavam que aparência do filhote de cisne era como descrita no conto "The ulgy duckling" - bem feio e esquisito. Desse modo, é importante destacar a influência que a descrição da imagem do pequeno cisne proposta no conto de Andersen tem sobre os leitores, revelando a intenção de transmitir a ideia de que o diferente causa desconforto, através das falas insultuosas dos outros animais. Dando continuidade ao diálogo, intentamos compreender por qual razão a história tenciona para que um dos animais seja visto como "feio":

Pesquisadora: So why was the "ugly duckling" considered ugly? (Então, por que o "patinho feio" foi considerado feio?)

Participante A.C: Ele não era feio, os outros patinhos só não aceitavam ele, porque ele era diferente deles.

Participante C.T: Só porque ele tinha a cor e o tamanho diferente. No conto diz que ele era grande.

Participante C.E: Na verdade ele não era nem pato, era cisne e só chamaram ele de feio, porque ele não era igual aos outros patinhos.

Podemos observar que os participantes se mostram bastante seguros de que a não aceitação do pequeno cisne, por parte dos patinhos, ocorre por conta da sua penugem ser de uma coloração diferenciada do restante do bando, além do fato dele ser visivelmente maior. Em outras palavras, as características físicas do pequeno cisne implicaram diretamente para que ele não fosse aceito por aquele bando. Aqui, é possível compreender que a percepção crítica dos aprendizes é estimulada à medida em que são questionados sobre a aceitação da aparência do personagem.

Uma das principais características do letramento crítico é permitir que, por meio da leitura de textos fictícios, possamos estabelecer debates sobre assuntos reais, que impactam direta e diariamente na vida dos aprendizes. São as leituras de mundo atravessadas pela leitura da palavra, conforme Freire (1970) nos ensinou. A fim de nos aprofundarmos nessa tensão entre texto e contexto, consideramos oportuno criar um cenário onde os personagens do conto de Andersen fossem cambiados por pessoas e situações hipotéticas, comuns do nosso cotidiano. Para tanto, fizemos o uso de representações de situações Revista X, v. 16, n. 6, p. 1684-1710, 2021. 
válidas para o debate em torno do racismo e da gordofobia. Reconhecer que o racismo e a gordofobia estão muito presente nos discursos e nas práticas escolares, é primordial para promovermos uma educação livre de preconceitos e o primeiro passo para que isso ocorra é compreender que essas práticas reproduzem uma ideologia maior, que defende que sujeitos ocupem uma posição de inferioridade em relação a outros

Desse modo, demos continuidade ao debate, objetivando tornar efetivo e constante o discurso antirracista e antigordofóbico, assim sendo, na primeira imagem apresentamos um grupo de três crianças, dois meninos loiros e uma menina negra, com isso, optamos inicialmente por uma problematização de cunho racial, a fim de compreender como os participantes reagem a situações de racismo dentro e fora do ambiente escolar:

Figura 3: Neste caso, quem seria o "patinho feio"?

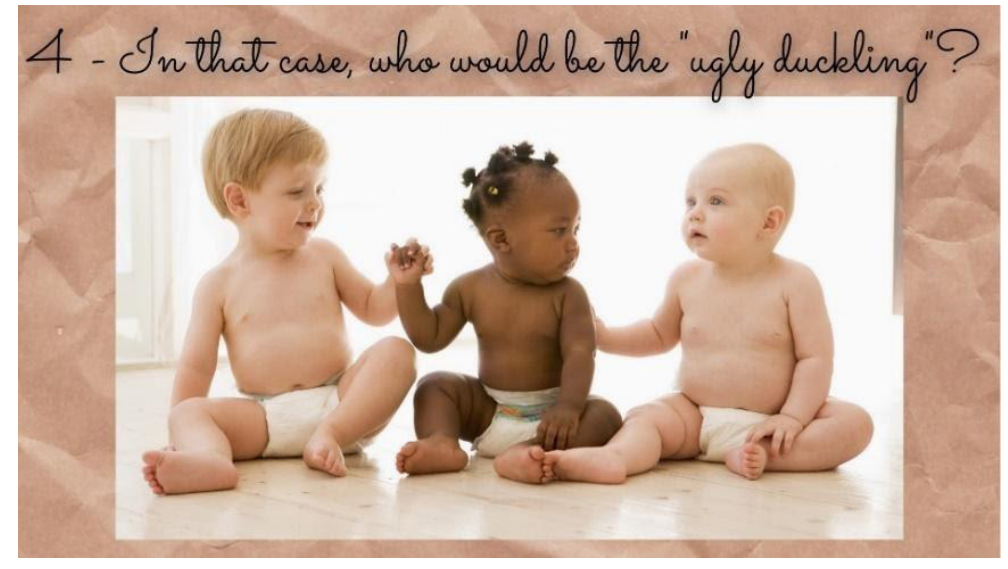

Fonte: The Learning Professor ${ }^{1}$

Ao opinar sobre quem eles achavam que poderia ser considerado o "patinho feio" na Figura 2, os aprendizes também resgataram episódios em que presenciaram falas racistas, deixando evidente os seus posicionamentos contra as falas relatadas:

Participante C.T: A do meio, porque é negra.

Participante E.K: Também acho que a do meio seria considerada o patinho feio.

Participante A.C: É, também penso que seria a do meio, porque infelizmente muita gente ainda pensa de forma muito racista. A avó da minha prima uma vez disse que todo negro é feio, eu fiquei sem reação quando ela disse isso.

1 Disponível em: <https://learningprofessor.com/product/social-emotional-development-thefoundation-for-all-curriculum/> Acesso em: 01 maio de 2021. 
Participante F.A: Eu já escutei alguém dizendo isso, ele falou tipo de brincadeira. Mas isso é muito sério. Também acho que seria a menina que seria o patinho feio.

Dispondo do que foi debatido anteriormente, sobre o posicionamento dos aprendizes quanto ao racismo, consideramos pertinente comentar sobre a reação da turma ao assistir uma propaganda de um produto de limpeza, em um outro momento do encontro. $\mathrm{O}$ anúncio, que se tornou alvo de duras críticas, é descrito pelo G1 como "a propaganda mais racista do mundo". O referido vídeo é uma comercial de uma marca chinesa, criado com o intuito de demonstrar a eficácia de um determinado produto de limpeza. O conteúdo do vídeo consiste basicamente na ação de uma mulher chinesa "lavando" um homem negro, que após o processo de "lavagem", surge com a aparência de um homem chinês, de pele clara.

Questionamos o que os aprendizes acharam do vídeo e por qual motivo a mulher realiza aquela ação, os alunos prontamente apontaram o racismo como a principal causa. Abaixo, podemos observar as respostas dadas pelos participantes, observadas no material de suporte pedagógico:

Participante A.C: (Pergunta 7) - Achei um absurdo, pois em pleno século 21 as pessoas ainda tratam os negros desse jeito.

(Pergunta 8) - Porque ela é muito racista, para ela somente pessoas da "espécie" dela são bonitas, como no patinho feio.

Participante F.A: (Pergunta 7) - Achei pesado! Deveria ter punição para esse tipo de propaganda.

(Pergunta 8) - Porque ela é racista, tratou a cor da pele do homem como suja.

Participante C.E: (Pergunta 7) - Eu acho o vídeo racista. Pois trata a cor da pele dele como se fosse uma sujeira.

(Pergunta 8) - Porque ela é racista.

Selecionamos algumas respostas dos aprendizes, com o intuito de analisar os seus posicionamentos diante de uma situação de preconceito racial. Além do sentimento de revolta e indignação expressado pelos aprendizes, podemos observar que um dos participantes faz uma ligeira comparação do preconceito entre "espécies" visto no conto The ugly duckling ao preconceito racial verificado no vídeo. Além do mais, nos chamou a atenção, a maneira como os participantes F.A e C.E observam a atitude da mulher do vídeo, assinalando que a cor do homem negro é tida como "suja" para a personagem.

Observamos, portanto, como a prática do letramento crítico é importante no sentido de que, por meio dela é possível despertar a consciência do aprendiz sobre seu 
discurso ativo na produção e reprodução de sentidos, a partir da perspectiva da leitura de um conto de fadas. Em termos metodológicos, essa tarefa é um bom exemplo do que seriam as práticas de compreensão do design de textos, conforme elaborado por Janks (2010) em sua orientação para o desenvolvimento de letramento crítico. A partir da imagem e vídeo apresentados, os aprendentes puderam observar como os textos podem ser construções discursivas representativas de discursos hegemônicos excludentes.

Retomando a sequência da atividade, apresentamos uma situação em que estão presentes um grupo de garotas, onde uma se destaca visivelmente pelo seu porte físico ser destoante das demais moças. Neste sentido, esperamos por meio deste questionamento compreender o posicionamento dos participantes em relação a prática da gordofobia tão presente no cotidiano escolar:

Figura 4: Neste caso, quem seria o "patinho feio"?.

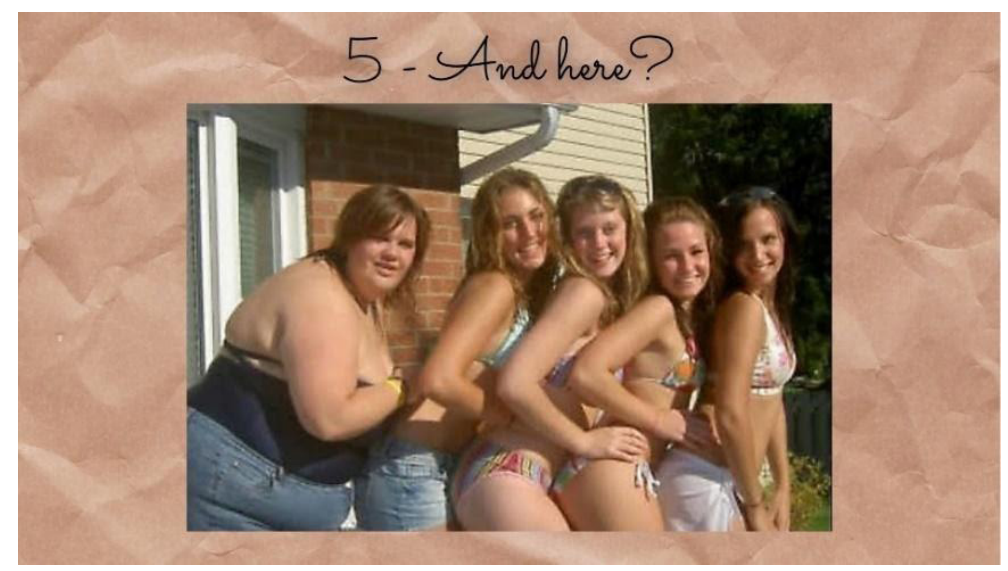

Fonte: Just That Fat Girl ${ }^{2}$

É importante observar como o debate conduz os aprendizes ao nível de autorreconhecimento em situações advindas do conto e partir de então começar a “estranhar" o mundo ao seu redor, como sugere Luke (2018), permitindo-lhes se posicionar frente a situações que lhes ponham em posição tais quais a que é relatada no conto. No trecho abaixo, um dos aprendizes apresenta esse discurso de autorreconhecimento:

2 Disponível em: <http://justthatfatgirl.blogspot.com/2012/06/kids-can-be-cruel.html> Acesso em: 01 maio de 2021.

Revista X, v. 16, n. 6, p. 1684-1710, 2021. 
Participante A.C: A do canto, porque ela é gordinha e geralmente as pessoas tiram muitas brincadeiras bestas com quem é gordinho. Aqui na escola só o que tem.

Participante C.E: É sim, a moça que é gordinha seria o patinho feio.

Participante F.A: É, eu concordo com A.C, aqui na escola, muita gente brinca desse jeito. Já me chamaram muito de "baleia", só que eu nem ligo mais.

Apesar de alguns alunos terem se engajado na discussão, nem todos se viram na necessidade de se posicionarem, o que pode estar relacionado à falta de debate na escola ou em casa. Como são rotineiras as ações de bullying as quais os alunos são acometidos, como foi relatado por um dos participantes, se faz necessário o resgate de debates em torno dessa causa. Buscamos entender se a conscientização por meio de acontecimentos reais conseguiria despertar a sensibilidade dos aprendizes. Desse modo, apresentamos recortes de matérias cujas principais causas para os acontecimentos era o bullying na escola, ainda questionamos se as relações entre os alunos têm alguma similaridade com as situações apresentadas nas imagens anteriores e os resultados obtidos mostraram que sim:

Participante C.T: Ora não! Como F.A disse. Eu vejo mais assim, as pessoas rindo do corpo, das roupas, às vezes porque usa óculos, essas coisas. Eu sei que tem gente que não faz maldade, como às vezes eu faço com meus amigos, por isso é que tem que ser falado, como a gente tá fazendo agora.

Participante C.E: Hoje em dia tá mais dificil aqui na nossa sala, mas quando a gente tava no $6^{\circ}$ e $7^{\circ}$ ano, era direto. Eu me lembro do povo fazendo piada com F.A e J.C. Mas acho que nas outras séries ainda tem muito.

Participante A.C: Quando eu estudava com a outra turma, quase toda semana eu ia pra diretoria com outra menina, porque eu não aguentava elas me chamando de "dente de coelho" e sei lá o que. Eu ficava com raiva demais e findava brigando, só que tem gente que fica guardando e é pior.

Após serem questionados sobre a prática de bullying na escola, apresentamos os recortes das matérias, a fim de gerar um impacto na turma e sinalizar que o bullying, apesar de aparentar, não pode ser enxergado como uma realidade normal no ambiente escolar. Deste modo, obtivemos os seguintes relatos:

Participante F.A: Foi basicamente o que aconteceu com o irmão de I. do $9^{\circ} \mathrm{B}$, dizem que até o pai dele humilhava ele porque ele era gordo demais e na escola era pior. Ai ele não aguentou e se matou. 
Participante A.C: Mas parece que não serviu de nada, porque eu já vi um monte de vezes o povo do $9^{\circ} \mathrm{B}$ tirando brincadeira de mal gosto com I. por ele ser gordinho também.

Participante C.E: É verdade, também já vi e a gente percebe que ele não se sente bem, fica só rindo bem sem graça.

A partir dos excertos apresentados acima, logramos observar como as práticas de letramento crítico levaram os aprendentes a se movimentarem entre os significados literais e ideológicos dos textos lidos. A leitura aqui pôde ser vista como uma prática crítica multimodal (ROJO, 2019, p. 23) e relacional. Nesse sentido, os significados materializados nos mais diversos encontros semióticos foram reconhecidos e "estranhados" a partir de um encontro pessoal com os textos, uma experiência de autorreconhecimento que mobilizou experiências pessoais dos aprendizes e revelou suas leituras de mundo.

\section{CICLO DE REDESIGN: ETAPA DE CREATING}

A culminância do projeto "The different is not ugly" aconteceu por meio do que chamamos de "Creating". Essa prática se configura como uma etapa do ciclo de redesign, que de acordo com Jesus (2016, p. 36), "é um ato de transformação". Desta forma, nosso objetivo foi compreender o desenvolvimento da criticidade dos alunos por meio de suas produções de textos (Cartazes, história em quadrinho, vídeo, campanha em redes sociais). Nessa prática, os aprendizes desenvolveram suas criações a partir das análises e debates estabelecidos nos encontros anteriores, através das quais observaram e problematizaram diferentes identidades do patinho feio na vida real. Para tanto, foi estabelecido um encontro via Google meet, onde foram apresentadas sugestões de cartazes, pequenas peças teatrais e vídeos de campanhas de outras temáticas, a fim de possibilitar maior liberdade criativa nas produções. Desse modo, os próprios aprendizes definiram qual abordagem utilizariam como forma de chamar atenção das outras turmas da escola, para o tema em questão.

Durante o desenvolvimento desta etapa, os alunos tiveram uma semana para desenvolver suas produções. No decorrer desse período, procuramos estar presentes no grupo a fim de dar sugestões, ouvir suas ideias, refletindo em como suas produções poderiam estar relacionadas ao conto "The Ugly Duckling”, e, por fim, entender como suas visões e particularidades foram fundamentais para o desenvolvimento de suas criações.

Considerando a situação do ensino remoto, os participantes apostaram na ideia de uma campanha virtual com propostas de conscientização pela valorização da autoimagem e aceitação das diferenças e pelo fim das práticas de bullying na escola. As 
propostas foram implementadas por meio da disseminação de vídeos e cartazes nas redes sociais Instagram e WhatsApp. Um dos grupos emitiu uma solicitação à coordenação pedagógica da escola, sugerindo a elaboração do "mural da consciência", assim que as aulas retornarem ao modo presencial. Para sistematização da análise, as produções foram transcritas e discutidas seguindo a ordem de apresentação no último encontro.

\section{Produção 1}

Pesquisadora: O que lhe motivou a produzir esse video?

Participante A.C: Eu fiz para tentar mostrar para as pessoas que não existe essa coisa de dizer que as pessoas são feias, por ser diferente da maioria. Todo mundo é bonito igualmente do jeito que é. Porque eu também não quero que meus amigos se vejam como um patinho feio, como eu me via

Vídeo: - Olá, bom dia, boa tarde ou boa noite. Eu não sei que horas você vai tá vendo esse vídeo. É... eu vim hoje aqui falar sobre um assunto que me chamou bastante atenção, que é "diferente não é feio". Ser diferente da maioria das pessoas não é apenas um privilégio, mas também uma obrigação. Quando andamos na contramão do mundo somos notados, criticados, admirados, tudo ao mesmo tempo.

Imagina qual seria a graça se a gente fosse todos iguais, imagina como seria chato. Imagina você olhar para uma pessoa e ela ser igual a você, ter as mesmas características que você, ter as mesmas atitudes que você, ter a mesma beleza que você. Seria muito chato, né? você ser igual a todas as pessoas. Imagina se aquelas pessoas fossem perfeitas daquele jeito seguido padrões da sociedade, como seria chato, não? Bom, então venho hoje aqui dizer para você, você é perfeito do jeitinho que você é; sendo gordo, magro, baixo ou alto. Você é lindo jeitinho que você é! Você ser diferente das pessoas, não significa que você é feio. Você é lindo, linda, perfeito, perfeita, maravilhoso, maravilhosa. Tudo isso aos olhos de Deus, aos olhos da pessoa certa!

Através do seu discurso, a participante A.C apresenta uma mensagem de autoaceitação, ao passo que aparenta falar diretamente com alguém que passa por transtornos de autoestima, manifestando, dessa forma, um comportamento crítico em relação a uma situação da qual já foi vítima. O mesmo intuito de propagar o amor próprio pôde ser notado na segunda produção discente apresentada:

\section{Produção 2}

Pesquisadora: O que lhe motivou a produzir esse video?

Participante J.S: Passar a mensagem de que não importa o que os outros pensam de você, você deve se amar, porque ser diferente também é bom. 
Vídeo: - Não importa que digam que o seu cabelo não é legal, que a sua cor é estranha, que você é diferente. The different is not ugly!

O vídeo do Participante J.S apresenta um discurso positivo ao sugerir que ser uma pessoa "diferente" é algo bom, diferentemente do que ocorre com o personagem do pequeno cisne, no conto "The Ugly Duckling". Desse modo, o aprendiz expressa seu discurso crítico desconstruindo os sentidos atribuídos à ideia de ser diferente. Esse tipo de leitura é exatamente o que Luke (2018) sugere como competência crítica desconstrutiva, isto é, usar da materialidade discursiva como uma maneira de desafiar discursos ideológicos, criando uma espécie de contraponto, ou contra-discurso, que se opõe a uma realidade apresentada.

Diferentemente das exposições anteriores, a última apresentação do encontro síncrono, não se tratou de uma produção audiovisual. Os participantes lançaram uma proposta para criação de um mural nas dependências da instituição, nomeado por eles de "Mural da Conscientização", como uma proposta com fins de conscientização para a escola como um todo. Os aprendizes apresentaram um documento redigido por eles mesmos, elaborando uma solicitação à direção e à supervisão da escola para a criação do mural, assim que retornarem ao modo presencial de ensino. O documento foi assinado pelo diretor da instituição e pelos participantes (Participante C.E, Participante C.T e Participante M.H) responsáveis pela ideia de implementação do mural.

\section{Produção 3}

Pesquisadora: Mas por que vocês pensaram em criar um mural?

Participante C.T: Porque a gente sabe que na escola é onde mais tem esses problemas de bullying, brincadeiras sem graça que magoam as pessoas.

Pesquisadora: Então, para vocês, o mural seria uma forma de melhorar essa situação?

Participantes: (Resposta no chat) Sim!

Pesquisadora: E qual seria o conteúdo presente no mural?

Participante C.T: A gente pesquisou algumas imagens na internet, achamos bem interessante... Tipo colocar elas lá, botar umas matérias falando sobre bullying, essas coisas.

Mesmo não tendo as mesmas características das tarefas desenvolvidas pelos demais alunos, o grupo demonstrou uma proposta que sugere traços de criticidade, considerando a intenção dos participantes em criar materiais para estabelecer relações de conscientização no seu ambiente escolar. 
Os demais participantes não apresentaram seus projetos durante o encontro síncrono, deste modo não houve a possibilidade de debater acerca de suas produções. No entanto, o trabalho desenvolvido por esses aprendizes segue uma similaridade com os trabalhos apresentados anteriormente, construindo discursos de aceitação e conscientização.

Os trabalhos elaborados pelos participantes seguem uma ideia de campanha de conscientização, fundamentada e executada a partir da leitura do conto "The ugly duckling". Deste modo, as produções dos alunos podem ser vistas como uma forma de desconstrução do texto utilizado para a realização do projeto. Elas exteriorizam discursos carregados com posicionamentos críticos, mostrando como os aprendizes conseguem expressar suas insatisfações em discussões sobre os diversos tipos de preconceitos abordados no projeto "The different is not Ugly".

\section{CONSIDERAÇÕES FINAIS}

O objetivo central deste estudo foi observar se e como práticas pedagógicas desenvolvidas com base no desenho de letramento crítico proposto por Janks (2010), a partir do ciclo de redesign de textos, contribuíram para o desenvolvimento crítico de aprendizes de Língua Inglesa. Para este fim, tivemos como ponto de partida uma elaboração pedagógica, a qual nos referimos como projeto, cujo elemento central foi a leitura de uma versão do conto "The ugly duckling”.

Por meio do projeto realizado, conseguimos perceber as práticas de letramento crítico como experiências de aprendizagem através das quais os aprendentes puderam interagir uns com os outros, sendo capazes de compartilhar suas subjetividades de forma consciente e crítica. De maneira mais sistemática, pudemos observar o despertar da consciência crítica a partir dos trabalhos e diálogos produzidos pelos aprendentes ao longo do projeto, ao passo que se locomoviam dos sentidos literais para os sentidos ideológicos dos textos, conseguindo analisar e debater situações reais, mesmo tendo como base enquadramentos ficcionais de uma história de conto de fada.

Pudemos observar que a criticidade dos aprendizes pôde ser expandida através da realização de práticas de leitura em um ambiente de estudo remoto, desenvolvido durante o projeto e que esse ganho de criticidade trata-se de uma competência discursiva e dialógica. Ou seja, o acesso ao que chamamos de criticidade ou "consciência crítica" dáse através da materialidade discursiva, a partir dos esquemas de interação entre sujeitos e textos. Além disso, o projeto contribuiu para que os alunos pudessem se posicionar frente a questões de interesse social que os acompanham em suas experiências escolares, como é o caso do bullying. 
Apesar da grande relevância dessa pesquisa para a nossa compreensão sobre a criticidade como um construto de ordem discursiva e sobre o ensino crítico de línguas, a presente experiência de ensino nos mostrou o grande desafio de sermos professores críticos. Ao definirmos o desenho de um projeto didático, escolhendo textos e direcionando caminhos interpretativos, acabamos por sugerir posicionamentos adequados que deveriam ser seguidos pelos aprendentes. Por mais válida que essa mediação pareça ter sido sob um primeiro olhar, ela também é imbuída de uma certa crença de que os alunos não necessariamente enxergam certas camadas de sentido dos textos e consequentemente nos privamos de construir consciências críticas que partissem dos estudantes e de suas próprias vivências. Acreditamos que essa autocrítica, de modo algum, invalida os ganhos dessa pesquisa, mas trata-se de um ponto de partida para a elaboração de experiências futuras.

\section{REFERENCIAS}

ANDERSEN, Hans Christian. O patinho feio. Editora Melhoramentos, 1990.

BAKHTIN, M. Marxismo e Filosofia da Linguagem. $5^{\text {a }}$ edição, São Paulo, Hucitec, 1990.

BRYDON, D. 2011. Local Needs, Global Contexts: Learning New Literacies. In: MACIEL, R. F. e ARAÚJO, V. A. (Orgs). Formação de professores de línguas: ampliando perspectivas. Jundiaí, Paco Editora. Pp.105.

FAIRCLOUGH, Norman. Discurso e mudança social. Brasília: Editora UnB, 2008.

FREIRE, Paulo. Educação como prática da liberdade. $1^{\text {a }}$ ed. Rio de Janeiro: Paz e Terra, 1967.

FREIRE, Paulo. Pedagogia do Oprimido. Rio de Janeiro: Paz e Terra, 1970.

FROMM, Erich. Meu Encontro com Marx e Freud. 2a edição, Rio de Janeiro, Zahar, 1979.

GIROUX, Henry A. Rethinking education as the practice of freedom: Paulo Freire and the promise of critical pedagogy. Policy Futures in Education, v. 8, n. 6, p. 715-721, 2010 .

HORTON, Myles; FREIRE, Paulo. We make the road by walking: Conversations on education and social change. Temple University Press, 1990. 
JANKS, Hilary. Literacy and power. 1a ed. New York; London: Routledge, 2010.

JANKS, Hilary. Panorama sobre letramento crítico. In: JESUS, Dánie Marcelo de; CARBONIERI, Divanize. Orgs. Práticas de Multiletramentos e letramento crítico: outros sentidos para a sala de aula de línguas. Campinas-SP: Pontes editores, 2016, p. 21-39.

JESUS, Dánie; CARBONIERI, D. Práticas de multiletramentos e letramento crítico: outros sentidos para a sala de aula de línguas. Coleção: Novas perspectivas em Linguística Aplicada, v. 47, 2016.

LUKE, Allan. Two takes on the critical. In: Critical literacy, schooling, and social justice. Routledge, 2018. p. 216-224.

MONTE MÓR, Walkyria. Critical literacies in the Brazilian university and in the elementary/secondary schools: the dialectics between the global and the local. Formação de professores de línguas: ampliando perspectivas. Jundiaí: Paco Editorial, p. 307-318, 2011.

ROJO, Roxane; MOURA, Eduardo. Letramentos, mídias, linguagens. São Paulo: Parábola Editorial, 2019.

TEARLE, Oliver. A Summary and Analysis of Hans Christian Andersen's 'The Ugly Duckling' Fairy Tale. Interesting Literature. Disponível em: $<$ https://interestingliterature. com/2020/05/ugly-duckling-fairy-tale-andersen-summary-analysis/>. Acesso em: 17, Abril 2021.

TFOUNI, Leda Verdiani, Adultos não alfabetizados: o avesso do avesso. Pontes, 1988.

Recebido em: 03 ago. 2021.

Aceito em: 21 set. 2021. 